ISSN 1112-9867

\title{
THE STUDY OF NANO TECHNOLOGY UTILIZATION IN UPGRADING THE QUALITY OF CONSTRUCTION INDUSTRY WITH FIRE-ENGINEERING APPROACH
}

\author{
F. Hatami ${ }^{1, *}$ and S. H. Mousavi ${ }^{2}$
}

${ }^{1}$ Amirkabir University of Technology, Structure and Earthquake Research Center, ${ }^{2}$ Amirkabir University of technology

Published online: 11 June 2016

\begin{abstract}
Today, the first requirement for increasing quality and strength in construction industry is utilization of appropriate and high quality materials so that usage of these materials, in addition to reducing maintenance costs and also upgrading the structure's longevity, in engineering respect through change on weight reduction and increasing strength in used materials, can cause general strength of the structure against earthquakes and probable runs due to natural disasters. This requirement is very significant in passive defense scope and this task will be considered in used material in main structure of a building and also in used materials in its frontage and in terminology elaborate work. Given that one of the effects of fire on the building part and parcel of passive defense, so, this look from the perspective of fire engineering is also of particular significance. Wide studies have been performed in this ground and various factories are trying to increase their produced materials quality in today competitive world with utilization of various technologies. One of technologies considered today is Nano technology which in fact by changing the molecular structure of a material causes creating special properties in it and utilization of these properties can answer needs of producers and users for increasing quality, longevity, strength and weight reduction.
\end{abstract}

\footnotetext{
Author Correspondence, e-mail: hatami@ aut.ac.ir

doi: http://dx.doi.org/10.4314/jfas.8vi2s.70
} 
In this study, it is tried to introduce materials produced by Nano technology which have special properties like resistance against fire, settlement and weight reduction and increasing resistance in tolerance of strike and injected loads to the structure in defensive point of view in civil engineering scope.

Keywords: Nano technology; passive defense; building material.

\section{INTRODUCTION}

Security and safety are always considered among main human concerns. Then, man has been always seeking methods for reducing effects of elements threatening his safety and security [1]. Passive defense is imputed to a series of measurements that require utilization of individuals and decisions and with its implementation, we can prevent from causing financial damages to vital, sensitive and important military and non- military foundations and equipment and human fatalities or reduce the amount of damages and fatalities due to the enemy's offenses and air missile bombardment as much as possible. Passive defense includes locating, camouflage, covering, deployment and dissipation, defense, secure structures and reinforcement, deception and news annunciation [2]. Currently, the most significant aim of passive defense is immunizing and reducing vulnerability of people's necessary infrastructures so that gradually creates secure conditions, such important measurements have been done or are being performed in most countries of the world[3]. Major point in passive defense debate is that this issue is not considered merely from war and military explosions viewpoint and the effect of measurements in this scope for opposing against reduction of natural disasters impressions is also of special consideration. Special approaches in the construction industry (Fire Engineering), which can in this respect with regard to preventive measures of irreparable damage in the fire and then prevent.

The first step in construction of a resistant structure against prevenient destruction is to select appropriate materials [4]. Materials display various responses against dynamic loads than statistic loads. Under dynamic loading, materials reach enhancement that considerably promote the structure strength. Structures exposed to explosive loads for energy attraction enter the range of ultra-resilient transformations. As a result, materials constituting the structure should have ultra-resilient behavior and appropriate plasticity [3].

In our country, Iran, regarding to particular situation in Middle East region and continuous existence of external threats and also regarding to natural - geographical dimension and lying on earthquake faults, vicinity of habitats in the river route and flood plain regions and 
occurrence of problems and issues relating to water sources, passive defense finds a vital role in various dimensions [5]. One of technologies that can approximate us to this aim is Nan technology. Nano technology as a key and intercourse technology, has provided many opportunities for competition reinforcement in construction industry like faster, more flexible, more favorable, more stable and economic construction. And applied grounds of this technology, almost involves all parts of building including frame, frontage design,civil engineering (structure systems) and internal design. Materials properties' control in Nano scale and also control of relating physical and chemical effects makes the production of multipurpose construction materials with high efficiency possible that this task causes creation of additional value, strength increase, and quality and environment stability. It should be mentioned that this technology has a wide and considerable application in foundation of main infrastructures such as dams, paths, bridges and channels and so on[6]. In the next parts, besides introducing this technology, we study productions produced by this technology.

\section{NANO TECHNOLOGY IN CONSTRUCTION INDUSTRY}

Nano technology has been created from convergence of physics, chemistry and biology sciences. This technology has provided the ability of work in atom level and creation of structures that have completely new molecular order. Nano has Greek origin. Modified matter in Nano scale has new and useful properties that weren't observed previously in it. Nano technology creates the possibility of producing new materials, materials that potentially can have positive or negative effects on environment and hygiene [7].

New generation of buildings with usage of Nano technology can create a calm and soothing environment for man welfare and also fundamentally change the basis of designs and progress of construction industry through change of materials properties and features and consequently by producing incomparable productions such as lighter and more tenacious composites in respect of tension and constraint strength, covers with sufficient stability against fire and environmental destructive elements such as erosion, scratch and decay, sound proofs and sound absorbents, self-recovering materials with high longevity and so on and improve challenges like structures amendment and reconstruction, structures limited efficiency, saving in energy consumption, heat transfer reduction, required insulation and moisture preventing, structures strength and permanency increase, reduction of sonic pollutions , increasingstructures' efficiency and reduction of maintenance and repair costs, chemical 
corrosion like acidic rains and chemical mechanisms during administration and construction as destructive and restrictive elements[8].

Nano technology has a considerable role in construction industry. In this respect, steel, Concrete and glass industries have the greatest portion [9]. It should be mentioned that strength increase in construction materials will supply requirements of construction industry in defensive respect that in the following part, we will study materials produced with this technology. The following table shows main Nano technology domains in construction industry.

Table 1. Main domains of Nano technology in construction industry [9]

\begin{tabular}{|c|c|c|}
\hline Materials & Nano materials & Prospects \\
\hline Concrete & CNT-SiO2-Fe2O3 & $\begin{array}{l}\text { appropriate arming- } \\
\text { preventing from fraction }\end{array}$ \\
\hline Steel & copper Nano particles & $\begin{array}{l}\text { Weldability quality increase- } \\
\text { strength increase against } \\
\text { corrosion }\end{array}$ \\
\hline Window & $\mathrm{TiO} 2-\mathrm{SiO} 2$ & $\begin{array}{l}\text { Self-wiping- anti fog - anti } \\
\text { fire- preventing from heat } \\
\text { and UV beam permeation }\end{array}$ \\
\hline coverings and dyes & silver Nano particles- TiO2 & $\begin{array}{l}\text { Anti-fouling - property of } \\
\text { killing bacteria }\end{array}$ \\
\hline solar cells & TiO2-CNT-CdSe-C60 & $\begin{array}{l}\text { more efficient utilization of } \\
\text { solar energy }\end{array}$ \\
\hline Cement & $\begin{array}{l}\text { CNT-poly propylene Nano } \\
\text { fibers }\end{array}$ & $\begin{array}{l}\text { strength increase }- \text { resistance } \\
\text { against fire }\end{array}$ \\
\hline Sensors & $\mathrm{CNT}$ & $\begin{array}{l}\text { Timed monitoring of } \\
\text { structure health }\end{array}$ \\
\hline
\end{tabular}

\subsection{Concrete and high strength mortar}

One of challenges that have been created in construction materials field is production ofconcretes with high operation, high strength and permanence against inappropriate atmospheric conditions. Such resistant Concretes are produced from mixture of resistant cements along with other additives. Utilization of wind sinter, yarn, micro silica and polymers 
as additive causes improvement of Concrete properties, strength increase, more permanence and less corrosion and strength against corrosion. In recent decades, Nano structure materials, regarding to manifest behaviors which have displayed, have also been considered in industry and university. In this between, Concreteindustry is one of important users of Nano structure materials regarding to its needs whether in respect of strength, resistance, permanence or high performance [10].

Nano technology can help concretesreinforcement and also concreteanti-corrosion covers are produced using this technology. One of protection methods for Concretesexposed to corrosive environment conditions like thalassic environments is utilization of coats that prevent from permeation of external destructive elements inside concrete. This type of coat fills and polishes pores of concretesurface and moreover, is resistant against bad weather conditions, solvents, industrial detergents and corrosion [10]. Nano particles regarding to their very high specific surface and as a result very high surface energy act as atom core and create a strong cohesion with hydrated cement that consequently this effect due to high reactiveness of Nano particles hydration procedure continues and mechanical strength increases[11].

Nano silica improves particles density, increases Concretestrength and prevents from water penetration into concrete. Utilization of Titanium dioxide creates property of self-wiping and disinfecting and gives Concretewhite color and glitter. Nano carbon pipes are among other Concreteadditives which despite having a density about one sixth of steel density, have Young's modulus 5 folds of steel and their strength is 8 folds of steel. Such Nano additives can be used as an appropriate arming, with capability of bridging between cracks and dimension reduction and cracks transformation. Nano particle of hematite also causes Concrete strength increase [12].

\subsection{Steel}

Steel is one of the most important construction materials. Its properties such as strength, resistance to corrosion and welding capability are very important in design and construction. Weariness is a very sensitive matter that can lead to steel fracture in structures under cycle force (like bridges and towers). This matter can occur in tensions lesser than submission tension and consequently reduce the structure's profitable life. Tension increase causes beginning of crack and subsequently weariness fracture.Studies have shown that addition of copper Nano particles reduce steel surface inequalities and as its result tensions numbers are limited and therefore, crack due to weariness will slake. Progress in this technology leads to 
security increase, lesser need to supervision and better utilization of materials in constructions prone to weariness matter [13].

In welding discussion, the studies have shown that addition of Magnesia and calcium Nano particles more fragments grains of heated regions adjacent to weld in simple steel ( about one fifth of usual size) that this matter increases weld toughness. Toughness increase in weld connections not only causes permanency and increasing of structure safety but also reduces need to resources for connections establishment and as a result limit tensions in allowable level [13].

Mentioning this point is necessary that Nano particles in steel cause increase of strength ration to weight. Usage of Nano metals technology in construction causes production of Nano covers which need less maintenance and repair. Addition of Nano particles like molybdenum and vanadium to steel screws and beads causes strength increase of this equipment [13].

\subsection{Soil geotechnical strength increase}

One of methods of improving soil properties which has not been studied in the past is usage of Nano materials. Nano particles regarding to their high specific surface and surface load, cause inter particle interactions. Based on performed studies, we can say that Nano particles cause improvement of soils properties. The results show that addition of Nano silica to soil causes increase of volubility and doughy limit in soil and reduction of doughy domain which is significant in clay dams' core [14].

Soil Nano particles can exist in three forms: Nano plate, Nano wire or Nano pipe and Nano plot. They are known with their very small size, very large specific surface area (SSA), surface loads and their Nano cavities and therefore have coaction with other soil Nano structures in a very active form [15].

\subsection{Protection against fire}

Usage of thermal impediments is among necessary elements in building economy both in respect of investment costs for new constructions and structures reconstruction and in regard of operating costs. Nano technology provides various methods for extension of anti-fire materials and improvement of its properties and as substitute of polluting materials that had been used in this ground. Turning point of studies is silicate particles of Nano particles which are used as fillers of polymers and for raising properties of anti-fire and resistance to heat. In a building, polymers play an important role in cables covering. Anti- fire property of Nano clay composites indicate this matter that both heat waste and smoke extension is reduced considerably and time of combustion creation is delayed. Among other applied aspects of 
anti-fire cover is their utilization for wood, steel, plastic or concreteand fire extension in materials is delayed by this kind of cover and it prevents from uncontrolled fire extension[8]. Practical potentials of Nano technology, in this part of Nano particle covering materials which can be liquid or plastic are used for materials protection. In a ceramic cover, in case of fire occurrence in a few seconds, thermal impediment acts and strongly prevent from smoke extension. By using Nano powders, cover forms with more speed. So that concurrent with production of trapped gases, combustive products and water bubbles, secondary thermal impediment acts [6].
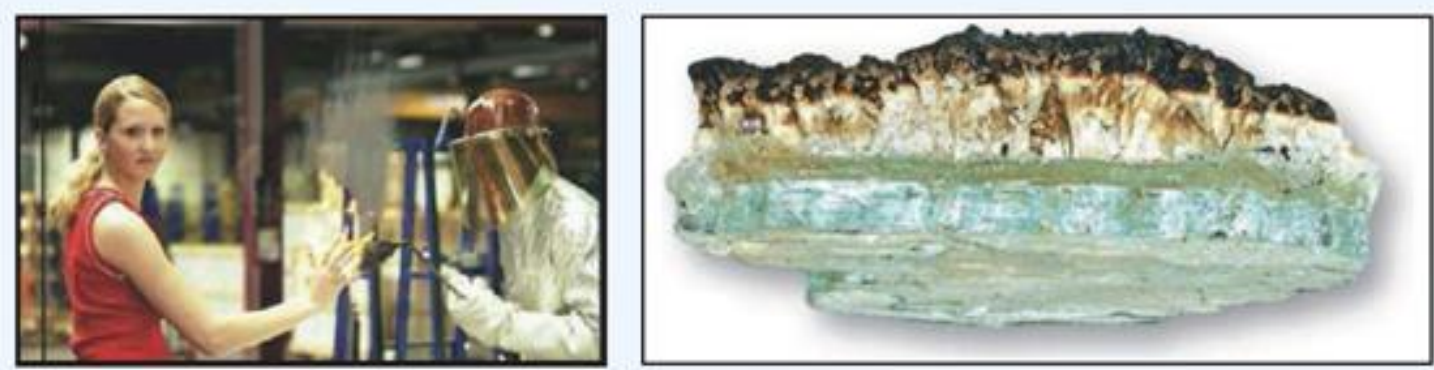

Anti- fire gels based on SiO2 modified Nano particles considerably increase anti- fire property of sidewalls. At the time of fire occurrence, a durable sponge layer is created which is not separated from glass surface[6].

\section{SENSORS}

Sensors based on Nano technology also can in turn have many applications in concretestructures. These sensors can be designed for various aims like density measurement, concretedownfall level, effective parameters in concretepermanence, rebar's corrosion and vibration for control of concretequality and permanence. Electronic complexity of these systems is lesser than usual systems but is as much capable. They will have more energy efficiency and even can use their small solar cells for their energy supplement. Therefore, there is this capacity that structures are needless of maintenance and have more longevity and useful life and also with Nano sensors installation in the structure with the least cost the building status can simultaneously be identified and improved [8].

\section{CONCLUSION}

Due to existence of natural and human destructive factors and their effects on construction attention to high quality of suitable materials is very significant so that the researchers try to acquire the highest quality and efficiency from them by changing the structure of elements 
consisting construction materials and one of these ways has been usage of Nano technology which this paper tried to introduce the most important performed tasks and obtained results in construction industry with passive defense domain point of view. The prospect of passive defense in the production of materials that can view special effects (fire engineering) have remained in the building can be helped to reduce the damage caused by fire. Of course there is a point that researches in Nano technology domain have been much more than this and are extending every day, though still there is a long way before us and materials produced by this kind of technology should be examined from several aspects but we can point to their wonderful effects in considerable increase of resistance and strength of produced materials and also flexibility of materials against unfavorable effects of internal and external destructive factors.

\section{REFERENCES}

[1] Mehdi Khodaparast, Farhad Naebalsadrian. Passive defense in Iran ancient architecture, national congress of construction and permanent development, Iran, Mashhad, 2012.

[2] Tahereh Fatholahzadeh, Roghaieh Chaboki, Mohammad Javad Ghorbani, Significance and necessity of passive defense in cities, Iran's geopolitics council congress, Mashhad, 2013.

[3] Hossein Bakhshi, Hasan Arezoo,Ali Gholamreza Pournoghani. Structure requisites and architecture of hospitals construction with passive defense approach, Iran's national congress of construction and permanent development, Mashhad, 2012.

[4] Reza Abbasnia, Abolfazl Yosefpour Avarandi, Mohammad Mahdi Javidan. Guidelines of buildings designing for proceeding destruction and passive defense, national conference of civil engineering and Iran permanent development.

[5] TaherehSadeghlo, Hamdolah Sajasi Gedari. Provision of a conceptual pattern of crisis management with passive defense approach, Iran's geopolitics council congress, Mashhad, 2013.

[6] Fatemeh Sadat Hosseini, Saeid Mohammadi Yazdi. Applications of Nano technology in construction industry (in Germany) series of records of Nano technology observation, 2012.

[7] Hadi Mahmoudpoor, Meitham Ghasem Esmati. Utilization of Nano technology in construction industry and architecture spaces and its effects on environment, the second congress of universal environment, energy and biodefense congress. 
[8] Seyed Javad Alamdar, Pouriallderabadi. The study of existing challenges in the path of universalization of usage of Nano technology in construction science, international conference of civil engineering architecture \& urban sustainable development, Tabriz, 2013

[9] Kaveh Karimi. The study and utilization of Nano technology in construction industry, the first national congress of architecture, repair, urbanity and sustainable environment, 2013.

[10] Soroush Ghaderi, Fazlolah Soltani. Usage of Nano technology in improvement of Concretefeatures the first national conference of Concreteindustry, 2012.

[11] Amir Modarres, Morteza Rahmanzadeh. Evaluation of Nano particles usage in Concrete superstructure, international conference of civil engineering architecture \& urban sustainable development, Tabriz, 2013.

[12] Janbozorgi, Z Ghanad. Nano technology utilization in construction industry, theoretical scientific magazine of Keison, 2010.

[13]Fereshteh Malekpour, mohammad Hossein Tavakoli Dastjerdi. Nano technology utilization in Meta structures, universal system of Nano technology training, 2015.

[14] Hadi Salimi, Mohsen Karami, Mostafa Mohammadi. Laboratory examination of Nano silica effect on soil geo technique characteristics, national congress of structure, path architecture, Chaloos, 2011.

[15] Seyed Alireza Seyedi Golsefidi, Mohammad Hossein Baziar, Seyed Mohammad Mirkazemi, Hamed Ghazi. Nano technology usage in Geo technique engineering, the first national conference of construction and development, Zibakenar, 2011.

\section{How to cite this article:}

Hatami F and Mousav S. H. The study of Nano technology utilization in upgrading the quality of construction industry with fire-engineering approach

J. Fundam. Appl. Sci., 2016, 8(2S), 558-566. 